\title{
Paper
}

\section{Process of Molybdenum Powder Elution in Water}

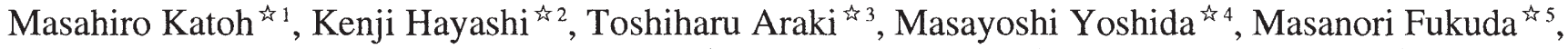

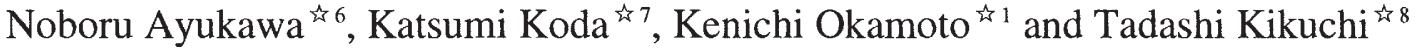 \\ 41 A.L.M.T. Corp., 2 Iwasekoshi-machi, Toyama 931-8543, Japan. \\ if 2 A.L.M.T. Tungsten Corp., 2 Iwasekoshi-machi, Toyama 931-8543, Japan. \\ ${ }^{3}$ Toshiba Nanoanalysis Corporation, 8 Shinsugita-cho, Isogo-ku, Yokohama 235-8522, Japan. \\ \&4 ${ }^{2}$ anasonic Corporation, 1-1 Saiwai-cho, Takatsuki 569-1193, Japan. \\ मै5 Japan New Metals Co., Ltd., 1-6-64 Sennari-cho, Toyonaka 561-0829, Japan. \\ is 6 Nippon Tungsten Co., Ltd., 3173-2 Sonobe, Kiyama-cho, Miyaki-gun, Saga 841-0203, Japan. \\ is 7 Toho Kinzoku Co., Ltd., 26-5 Ikedanishi-machi, Neyagawa 572-0036, Japan. \\ ${ }^{2}{ }^{8}$ Tokyo University of Science in Yamaguchi, 1-1-1 Daigaku-dori, Sanyo-Onoda 756-0884, Japan.
}

Received November 8, 2010

\begin{abstract}
SYNOPSIS
As the starting material of molybdenum manufactured by powder metallurgy, molybdenum powder is used. To investigate the elution in water of the molybdenum powder used as a raw material, the molybdenum elution was analyzed by ion chromatography and X-ray photoelectron spectroscopy (XPS). It was clarified that the elution based on $\mathrm{MoO}_{4}{ }^{2-}$ takes place as determined by ion chromatography. Results of the surface measurement by XPS revealed that, the molybdenum oxidized in air on the surface exists mainly as molybdenum (VI) oxide $\left(\mathrm{MoO}_{3}\right)$, which is the most stable oxide. The molybdenum (VI) oxide elutes promptly in water compared with the metal powder. The oxide on the molybdenum metal surface, which was assumed to be eluted promptly, became thin, and the elution was repeated again by oxidation in water through molybdenum (IV) $\left(\mathrm{MoO}_{2}\right),(\mathrm{V})\left(\mathrm{Mo}_{2} \mathrm{O}_{5}\right)$ and (VI) oxides, and the solution was clarified to elute through molybdenum (VI) oxide.
\end{abstract}

KEY WORDS

molybdenum powder, elution behavior in water, ion chromatography, X-ray photoelectron spectroscopy

\section{Introduction}

The metal molybdenum is mainly produced by powder metallurgy, since it has a high melting point, and is mainly used as a heat-resistant material such as a furnace component. In particular, in molybdenum manufacturing, wherein it is dispersed in water as a rare-earth oxide to improve the high-temperature deformation resistance ${ }^{1)}$, there is a case in which water and molybdenum oxide remain, and it is important to prevent the molybdenum elution in the solvent water, since the product will have insufficient density in this case. The authors have examined the elution amount of the molybdenum elution in water with the parameter of the temperature, grain size and acid and alkali added to the solution ${ }^{2}$. Consequently, it can be suggested that a manufacturing condition with low molybdenum elution can be achieved using metallic molybdenum or $\mathrm{MoO}_{2}$ as the raw powder, as well as with the use of purified water maintained at a low temperature. Moreover, the elution is markedly different depending on the oxidation state of the molybdenum, and over $95 \%$ is dissolved in four weeks if it is not a molybdenum (IV) oxide but a molybdenum (VI) oxide.

The control of molybdenum elution and removal from the solvent water are important, and advance the manufacturing process is required. However, research on molybdenum elution in solvent water has hardly been carried out. As for reports concerning the oxidation of molybdenum, Abello et al. used X-ray photoelectron spectroscopy (XPS) to determine the reduction of molybdenum on the surface of $\mathrm{Al}_{2} \mathrm{O}_{3}{ }^{3)}$, and Spevack and McIntyre used XPS with Raman spectroscopy to study the molybdenum oxide thin film; this study was undertaken with calcination and reduction ${ }^{4}$. However, there is almost no research involving the observation of molybdenum surface oxidation and chemical state before and after molybdenum elution in water. Concerning the elution of molybdenum, Shoji et al. ${ }^{57}$ reported differences in $\mathrm{pH}$ even in the case of the most stable molybdenum (VI) ion $\left(\mathrm{MoO}_{2}{ }^{2+}\right)$ of the molybdenum dioxide ion and $\left[\mathrm{Mo}_{7} \mathrm{O}_{24}\right]^{6-}$ of the isopoly acid of the paramolybdate ion. Moreover, Saito ${ }^{6)}$ reported the existence of $\mathrm{MoO}_{2}{ }^{2+}, \mathrm{H}_{2} \mathrm{MoO}_{4}, \mathrm{H}_{2} \mathrm{Mo}_{7} \mathrm{O}_{24}{ }^{4-}, \mathrm{HMoO}_{4}^{-}$, $\mathrm{HMo}_{7} \mathrm{O}_{24}{ }^{5-}, \mathrm{Mo}_{7} \mathrm{O}_{24}{ }^{6-}$ and $\mathrm{MoO}_{4}{ }^{2-}$ as molybdenum (VI) 
ions; molybdenum exists particularly as $\left(\mathrm{MoO}_{4}{ }^{2-}\right)$ at $\mathrm{pH}$ $6.5-11$.

In this study, the oxidation state and depth profiles were examined by XPS, the sensitivity of which was high with respect to how the oxidation state of the molybdenum surface changes on a solid-fluid interface between molybdenum and water. Moreover, the ionic state of the eluting oxidized molybdenum of $\mathrm{MoO}_{4}{ }^{2-}$ was determined by ion chromatography.

\section{Experimental}

Metal molybdenum powder of $2.9 \mu \mathrm{m}$ average particle size (Fischer Sub-Sieve Sizer) and molybdenum oxide powders $\left(\mathrm{MoO}_{2} 1.5 \mu \mathrm{m}, \mathrm{MoO}_{3} 3.3 \mu \mathrm{m}\right)$ were used as the samples. $\mathrm{Mo}, \mathrm{MoO}_{2}$, and $\mathrm{MoO}_{3}$ are made by A.L.M.T. Corp. $\mathrm{MoO}_{2}$ and $\mathrm{MoO}_{3}$ powders were used to confirm the crystal structures and oxygen ratios by $\mathrm{X}$-ray diffraction and thermogravimetric-differential thermal analysis, and these were used to identify the molybdenum (IV) and (VI) accurately. The oxygen content in these samples was estimated from the difference in weight right after and before the hydrogen reduction; samples were reduced (hydrogen reduction) at $1000{ }^{\circ} \mathrm{C}$ under hydrogen atmosphere after $0.5 \mathrm{~h}$ of heating.

The molybdenum powder $(1.0 \mathrm{~g})(1.5 \mathrm{~g}$ in the case of the $\mathrm{MoO}_{3}$ powder) was put in $1 \mathrm{~L}$ of purified water, then stirred with a stirrer for $0.5 \mathrm{~h}$, and the molybdenum concentration in the purified water after standing for $1 \mathrm{~h}$ was assumed to be the initial concentration. The amount of molybdenum eluted was measured in the purified water using an inductively coupled plasma atomic emission spectrometer (ICP-AES: Shimadzu ICP-8100) following the JIS K 0102 procedure. The purified water was obtained with an ion-exchange resin, and the $\mathrm{pH}$ was 7.9. Measurement of the chloride concentration using a residual chlorine checker (Tanita EW-510) showed that it was $0.0 \mathrm{mg} / \mathrm{L}$ and below the detection limit. The samples were made under the conditions shown in Table 1, and used in the analysis.

Analyses of the $\mathrm{MoO}_{4}{ }^{2-}$ ion in purified water were carried out by ion chromatography (Dionex Co. DX-120). Analysis conditions of the ion chromatography were as follows: separation column, Ion Pac AS14; eluate, $\mathrm{Na}_{2} \mathrm{CO}_{3}$ $3.5 \mathrm{mmol} / \mathrm{L}, \mathrm{NaHCO}_{3} 1.0 \mathrm{mmol} / \mathrm{L} ; 1.3 \mathrm{ml} / \mathrm{min}$ flow velocity. The suppressor was measured in the ASRS/ recycling mode, and each elution amount was calculated from the peak area of the standard solution $(40 \mathrm{ppm})$. Moreover, chemical analysis of this sample was carried out by ICP-AES.

Concerning the molybdenum elution in purified water, the chemical state evaluation was carried out by XPS (ULVAC-PHI Quantum2000). Measurement conditions of XPS were as follows: $\mathrm{Al} \mathrm{K} \alpha$ line, beam diameter of 100 $\mu \mathrm{m}$, and output of $25 \mathrm{~W}$ in the primary energy. The sample molybdenum dried under vacuum was the precipitated after filtration of eluting in the purified water for four weeks. Carbon adhesion tapes were fixed to the sample stage, the samples were sprinkled on the carbon tape, then pressed and analyzed. All the binding energies were calibrated to $\mathrm{C} 1 \mathrm{~s}$ at $284.6 \mathrm{eV}$ of each carbon tape. There was no surface contamination as confirmed in the wide scan, and narrow peaks of Mo3d $\mathrm{d}_{5 / 2}$ and Mo3d $\mathrm{d}_{3 / 2}$ in steps of $0.1 \mathrm{eV} / \mathrm{sec}$ were measured. Between the peaks of $3 d_{3 / 2}$ and $3 d_{5 / 2}$, the intensity ratio of $0.66: 1$ and difference of $3.13 \mathrm{eV}$ were fixed; the peaks were separated and analyzed. The depth profile analyses were carried out with 10 times of argon ion etching ( $1 \mathrm{keV}$ ) (total of 10 minutes).

\section{Results and discussion}

3.1 $\mathrm{MoO}_{4}{ }^{2-}$ ion content and total molybdenum concentration The $\mathrm{MoO}_{4}{ }^{2-}$ concentration in the solution was measured by ion chromatography using the calibration curve method, because it was $\mathrm{MoO}_{4}{ }^{2-}$ of molybdenum (VI) at $\mathrm{pH}$ 6.5-11 condition; in the report of Saito ${ }^{6}$, the molybdenum powder eluted in water can exist in many states of molybdenum. The results are shown in Fig. 1. The molybdenum quantitative analysis was carried out using ICP-AES with respect to the solution analyzed by ion chromatography. The comparative results of the $\mathrm{MoO}_{4}{ }^{2-}$ ion content and the molybdenum total

Table 1 Sample preparation conditions.

\begin{tabular}{|c|l|}
\hline Sample No. & \multicolumn{1}{c|}{ Sample preparation conditions } \\
\hline No. 1 & $\begin{array}{l}1 \mathrm{~g} \text { of molybdenum is put in } 1 \mathrm{~L} \text { of purified water, } 0.5 \mathrm{~h} \text { of agitation is carried out, and then the } \\
\text { solution is allowed to stand for } 10 \text { days. }\end{array}$ \\
\hline No. 2 & $\begin{array}{l}1 \mathrm{~g} \text { of molybdenum is put in } 0.4 \mathrm{~L} \text { of purified water, } 0.5 \mathrm{~h} \text { of agitation is carried out, and then } \\
\text { the solution is allowed to stand for } 10 \text { days. }\end{array}$ \\
\hline No. 3 & $0.1 \mathrm{~mL}$ of $\mathrm{H}_{2} \mathrm{O}_{2}$ is added to $10 \mathrm{~mL}$ of solution in No.2. \\
\hline
\end{tabular}




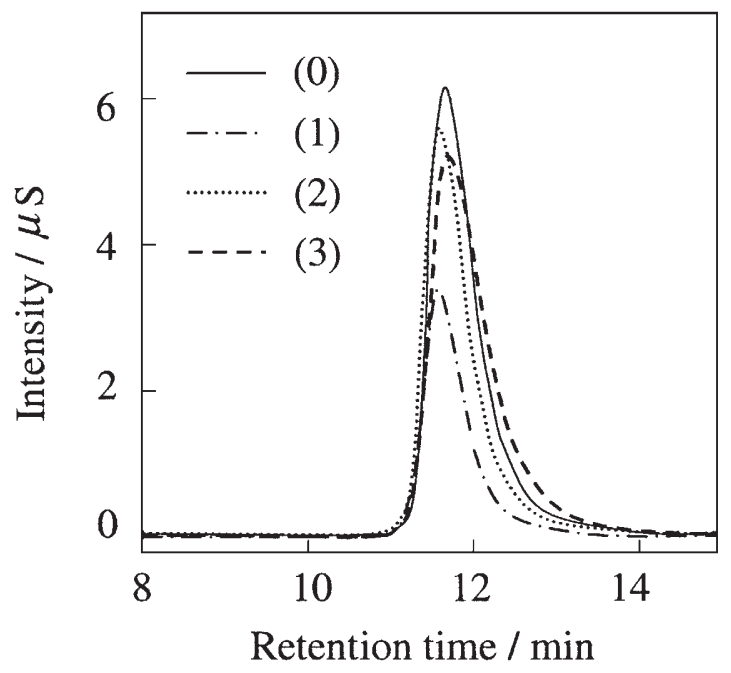

Fig.1 Ion chromatography spectra of $\mathrm{MoO}_{4}{ }^{2-}$ after the elution in purified water for ten days. (0) Molybdenum standard solution (40 ppm). (1) sample No. 1, (2) No. 2, (3) No. 3. concentration are shown in Table 2. As a result, it is difficult for $\mathrm{MoO}_{4}{ }^{2-}$ to exist if the quantity of molybdenum is large in the aqueous solution, and it becomes a chemical compound other than $\mathrm{MoO}_{4}{ }^{2-}$. Ions of water (aqua ion) including the molybdenum and water are molybdenum (II) (III) (IV) and (V), and it is necessary to consider the existing form of the ion when thinking that the molybdenum (V) aqua ion $\mathrm{Mo}_{2} \mathrm{O}_{4}{ }^{2+}(\mathrm{aq})^{7)}$ probably has the defined structure.

\subsection{Chemical state of molybdenum surface}

Concerning the elution of molybdenum in purified water, the measurement was carried out by XPS in terms of the chemical state of the surface before and after four weeks of elution. The XPS wide spectrum is shown in Fig. 2. In these samples before and after the elution, the peaks are only molybdenum and oxygen without observing the impurity except for the carbon that originates from the surface-adsorbed $\mathrm{CO}$ or $\mathrm{CO}_{2}$ and so on. The XPS quantitative analysis results are shown in Table 3 . Impurity elements present in the raw material were not measured.

Table 2 Comparison of molybdenum total concentration and $\mathrm{MoO}_{4}{ }^{2-}$ ion content.

\begin{tabular}{|c|c|c|l|l|}
\hline Sample & Color of water & $\begin{array}{l}\text { Ion Chromatography } \\
\left(\mathrm{MoO}_{4}^{2-} \text { ion content) }\right.\end{array}$ & $\begin{array}{l}\text { ICP-AES } \\
\text { (molybdenum total } \\
\text { concentration) }\end{array}$ & $\begin{array}{l}\text { Difference } \\
\text { (molybdenum } \\
\left.\text { except for } \mathrm{MoO}_{4}{ }^{2-}\right)\end{array}$ \\
\hline No.1 & Clear, colorless & 21 & 24 & 3 \\
\hline No.2 & Blue-tinged & 36 & 49 & 13 \\
\hline No.3 & Clear, colorless & 39 & 49 & 10 \\
\hline
\end{tabular}

Unit: mass ppm
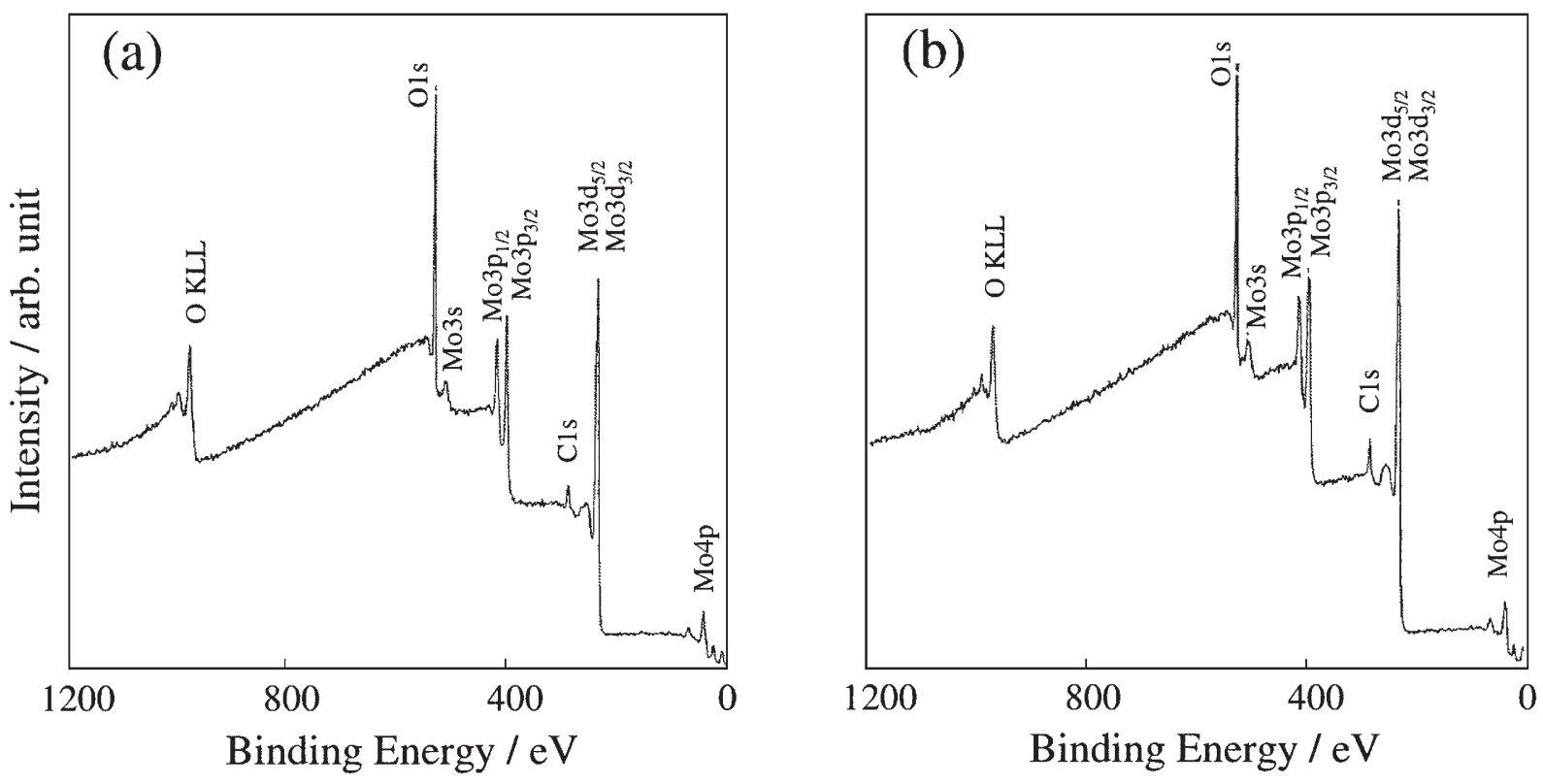

Fig.2 XPS wide spectra before (a) and after (b) the elution in purified water. 
Table 3 Molybdenum surface XPS quantitative analysis comparison before and after four weeks of elution in purified water.

\begin{tabular}{|c|c|c|c|}
\hline Molybdenum sample & O1s & Mo3d & C1s \\
\hline Before elution & 63.1 & 21.4 & 15.5 \\
\hline After elution & 52.3 & 26.9 & 20.8 \\
\hline
\end{tabular}

Unit: at. \%

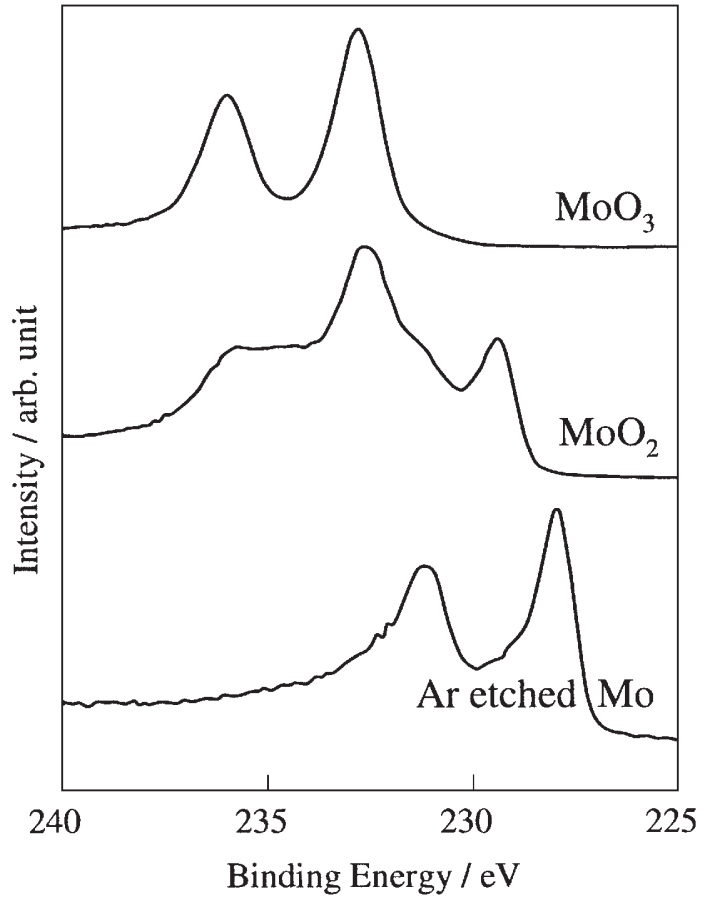

Fig.3 Mo3d narrow spectra of $\mathrm{MoO}_{3}, \mathrm{MoO}_{2}$ and molybdenum powder. Surface cleaning by argon ion etching is used for only the metal powder.

The $\mathrm{Mo} 3 \mathrm{~d}_{5 / 2}$ and $\mathrm{Mo} 3 \mathrm{~d}_{3 / 2}$ narrow peaks of $\mathrm{MoO}_{3}, \mathrm{MoO}_{2}$ and the metal molybdenum are shown in Fig. 3. Since the usual metal molybdenum powder surface is oxidized, surface cleaning by argon ion etching is used for only the metal powder. $\mathrm{MoO}_{3}$ peaks of $235.7 \mathrm{eV}$ and $232.6 \mathrm{eV}$ were corresponded to the peak energies determined by Patterson et al. ${ }^{8)} ; 231.3 \mathrm{eV}$ and $228.1 \mathrm{eV}$, which were the peaks of the metallic molybdenum ${ }^{8)}$ on the clean surface, were obtained after the etching. $\mathrm{MoO}_{2}$ peaks ${ }^{8)}$ of $232.5 \mathrm{eV}$ and $229.4 \mathrm{eV}$ were mixed $\mathrm{MoO}_{3}$ peaks because of surface oxidization. There was no change in the peaks of carbon and oxygen.

The Mo3d $\mathrm{d}_{5 / 2}$ and Mo3d $\mathrm{d}_{3 / 2}$ narrow peaks in the spectra of (a) molybdenum powder before elution and (b) the molybdenum that was dried after being eluted in the purified water for four weeks are shown in Fig. 4. Comparison of (a) and (b) shows that $\mathrm{MoO}_{3}$ peaks of 235.7 $\mathrm{eV}$ and $232.6 \mathrm{eV}$ shift to the low-energy side after elution.

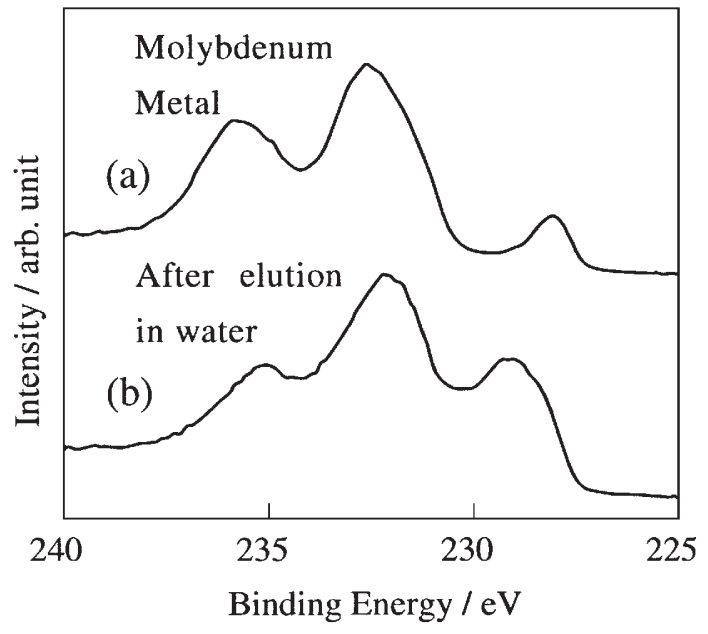

Fig.4 Mo3d spectra of molybdenum metal powder before (a), and after four weeks of elution in purified water (b).

The peak of the metallic molybdenum of $228.1 \mathrm{eV}$ shifts to the high-energy side.

Decomposition of Mo3d narrow spectra in terms of molybdenum oxidation number before and after elution in purified water is shown in Fig. 5; the distribution ratio of the molybdenum powder in the decomposition of Mo3d narrow spectra (at.\%) before and after the elution in purified water is shown in Table 4 . The peak shape of (a) showed a similar result of peak fitting to that of the $\mathrm{MoO}_{3}$ profile, as shown in Fig. 5 and Table 4 . When molybdenum peaks before and after the elution are compared, the quantities of molybdenum (VI) and molybdenum (0) were estimated to decrease from 80.2 at. $\%$ to 32.5 at. $\%$ and from 10.7 at. $\%$ to 6.2 at.\%, respectively. In contrast, the quantities of molybdenum (IV) and molybdenum (V) were estimated to increase from 2.0 at.\% to 34.8 at.\% and from 7.1 at. $\%$ to 26.5 at.\%, respectively. As shown in these results, the amount of molybdenum (VI) that remained on the surface seems to have decreased after the elution, since molybdenum (VI) dissolved in water. It is assumed that the delivery and acceptance of the electron occur between the inside molybdenum (0) and surface $\mathrm{MoO}_{3}$ and results in a condition whereby molybdenum (IV), (V) and (VI) 

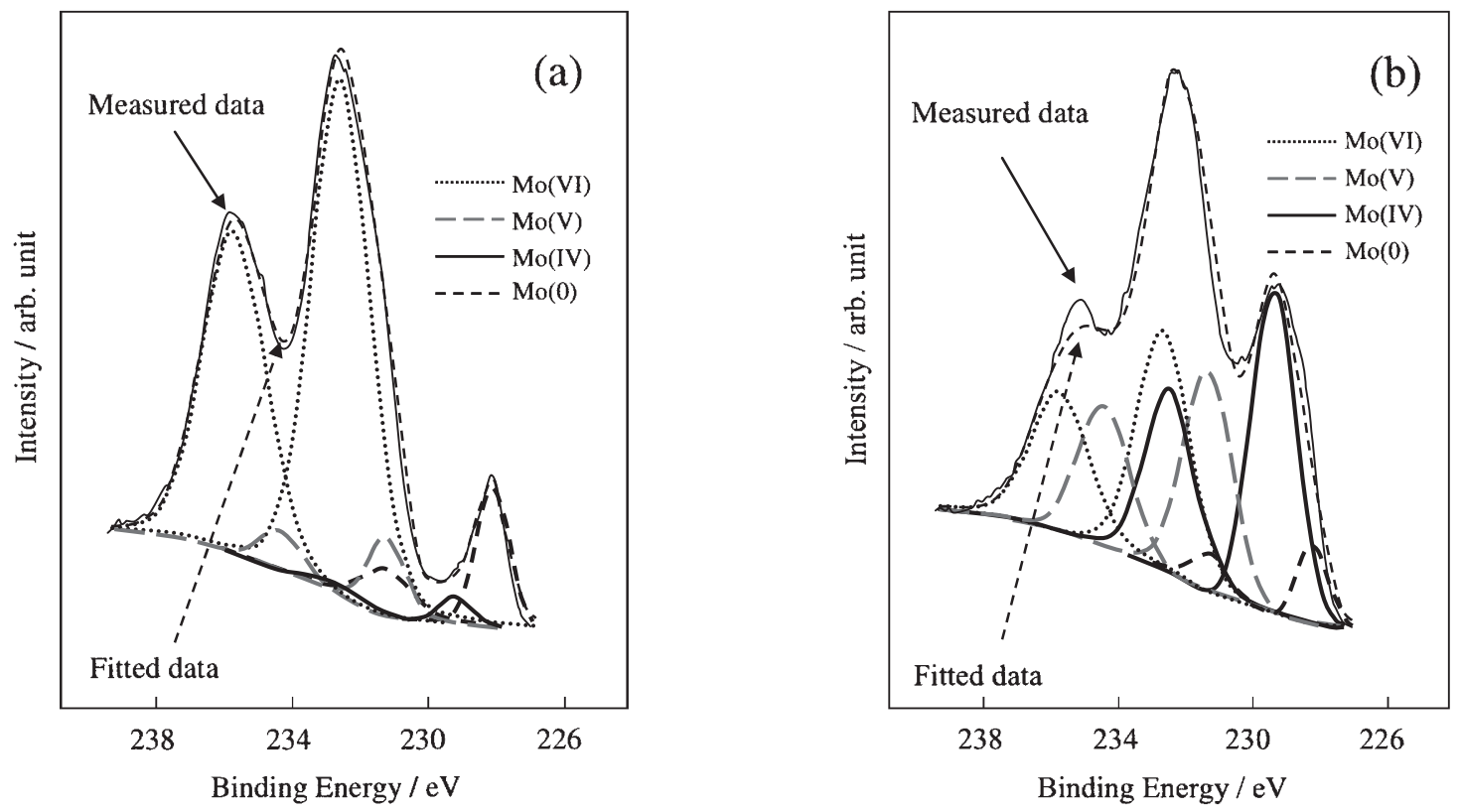

Fig.5 Decomposition of Mo3d narrow spectra in terms of molybdenum oxidation number before (a) and after (b) elution in purified water.

Table 4 Distribution ratio of the molybdenum powder in the decomposition of Mo3d narrow spectra (at.\%) before and after the elution in purified water.

\begin{tabular}{|l|c|l|l|l|l|}
\hline & \multicolumn{1}{|l|}{$\begin{array}{l}\text { Molybdenum } \\
(0)\end{array}$} & $\begin{array}{l}\text { Molybdenum } \\
\text { (IV) }\end{array}$ & $\begin{array}{l}\text { Molybdenum } \\
(\mathrm{V})\end{array}$ & $\begin{array}{l}\text { Molybdenum } \\
\text { (VI) }\end{array}$ & $\begin{array}{l}\text { Total } \\
\text { amount }\end{array}$ \\
\hline Before elution & 10.7 & 2.0 & 7.1 & 80.2 & 100 \\
\hline After elution & 6.2 & 34.8 & 26.5 & 32.5 & 100 \\
\hline
\end{tabular}

Unit: at. \%
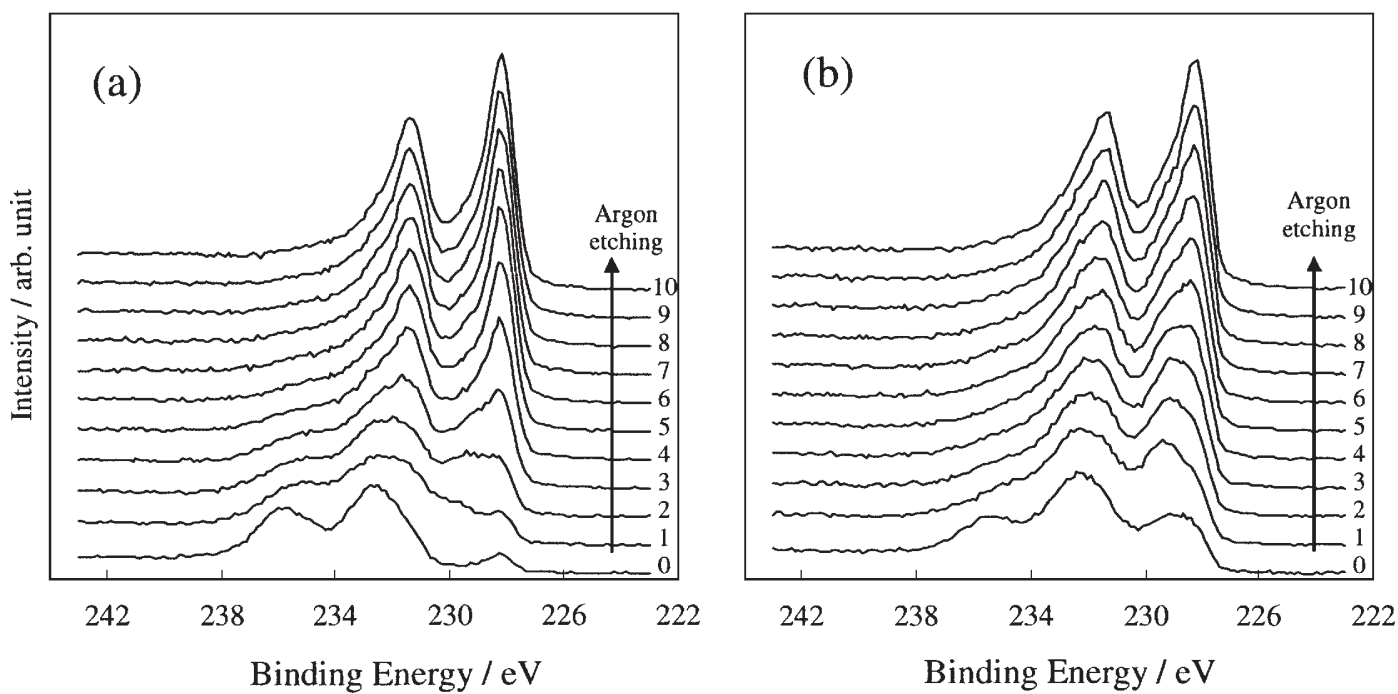

Fig.6 XPS depth profile of molybdenum powder determined with 10 times of argon etching at 1 minute each. (a) molybdenum metal powder and (b) the powder after four weeks of elution in purified water.

intermingle. The depth profile analysis results following 10 times of argon etching at 1 minute each obtained before and after the elution of molybdenum powders are shown in Fig. 6. Although this comparison was carried out assuming that surface oxidized layer thinning occurred in the powder after the elution, there was no large difference 


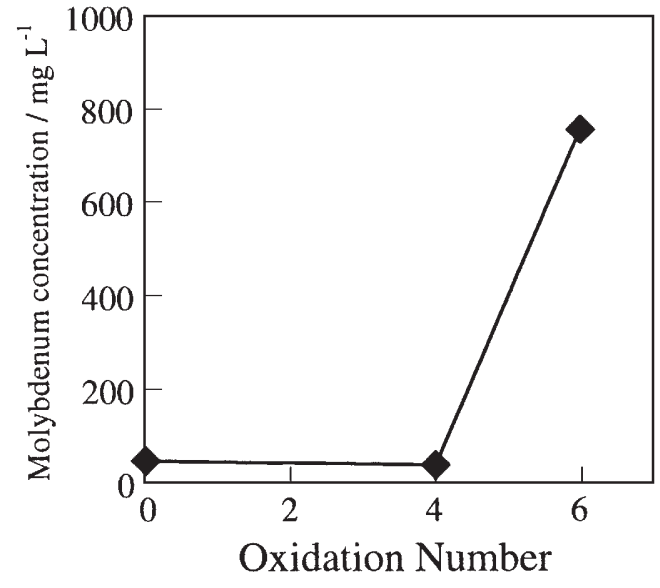

Fig.7 Relationship between molybdenum oxidation number and elution amount after four weeks.

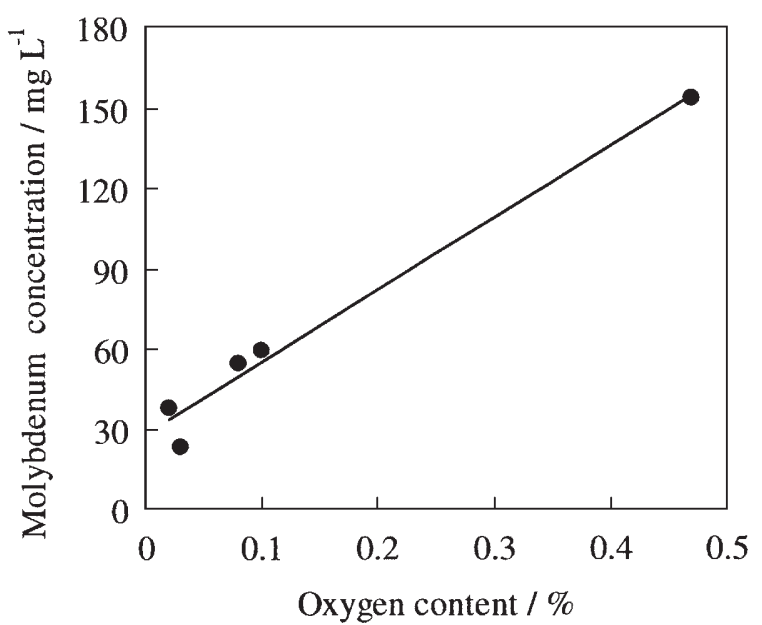

Fig.8 Relationship between oxygen content of molybdenum powder and elution amount of molybdenum.

before and after elution; the profile of the metal molybdenum was finally obtained after 6 times of argon etching at 1 minute each (total 6 minutes). It is assumed that the thicknesses of the oxide layer were not markedly different because the powder after elution is used for XPS after drying the filtrate.

\subsection{Elution mechanism}

Oxidation number and elution concentration of the molybdenum are shown in Fig. $7^{2}$. It is understood that the elution of $\mathrm{MoO}_{3}$ of molybdenum (VI) is very large, whereas the elution in water is small in the case of metallic molybdenum of molybdenum ( 0 ) and $\mathrm{MoO}_{2}$ of molybdenum (IV). The relationship between oxygen concentration and elution amount of the powder from $0.9 \mu \mathrm{m}$ to $7 \mu \mathrm{m}$ is shown in Fig. 8. It is proven that this tendency of elution amount to increase is one-dimensional, if the oxygen content of the molybdenum powder is high. Naturally, the oxygen content of an initial amount of molybdenum powder shows

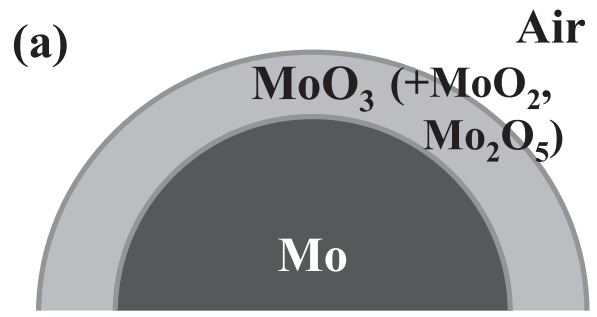

(b)

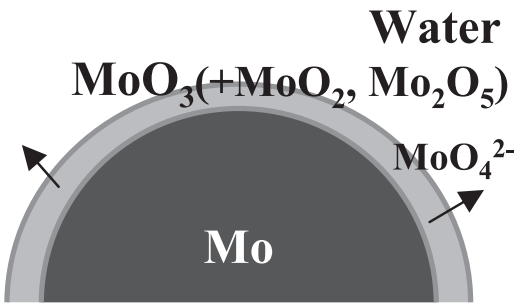

(c)

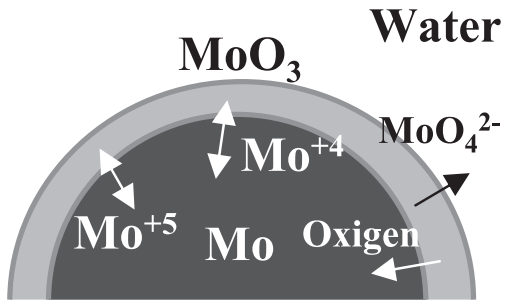

Fig.9 Assumed elution process from the molybdenum to the water. (a) Molybdenum powder oxidized surface in air. (b) $\mathrm{MoO}_{3}$ of the surface quickly elutes out by soaking in water. (c) The oxygen supplied from the surface gradually oxidizes the molybdenum of the base material, and the elution in the water of the molybdenum occurs through the oxide.

the tendency to increase as the specific surface area increases (with a small particle size). The assumed elution mechanism is shown in Fig. 9. It becomes $\mathrm{MoO}_{3}$ of molybdenum (VI), which is the most stable oxidation layer, to molybdenum (IV) and (V), which is an intermediate layer. The elution rate seems to rapidly increase, with oxidation becoming $\mathrm{MoO}_{3}$ and $\mathrm{MoO}_{4}{ }^{2-}$ (molybdenum (VI)) rather than metallic molybdenum, molybdenum (IV) and (V). It is assumed that the oxidation and the elution are repeated by displacement oxygen near the molybdenum surface.

\section{Conclusions}

In this study, the oxidation state and time variation of the elution of molybdenum were examined using XPS, the sensitivity of which was high with respect to how the oxidation state of the molybdenum surface changes on a solid-fluid interface between molybdenum and water. Furthermore, ion chromatography was carried out with respect to the ionic state of the eluted molybdenum oxide. The results were as follows.

(1) We could determine the elution amount of $\mathrm{MoO}_{4}{ }^{2-}$ in 
solution by ion chromatography, and it was proven that the elution in which $\mathrm{MoO}_{4}{ }^{2-}$ becomes the main form occurred at the stage of little molybdenum input.

(2) Surface analysis by XPS showed that the amount of $\mathrm{MoO}_{3}$ on the powder surface after elution decreased as compared with that before the elution.

(3) The elution tests showed that the elution of $\mathrm{MoO}_{3}$ is larger than that of the metallic molybdenum and $\mathrm{MoO}_{2}$. Therefore, if the oxygen content of an initial amount of molybdenum is high, the elution amount will also be high.

The molybdenum oxidized in air exists as an oxide of the most stable molybdenum (VI) on the surface. In the water, it rapidly elutes as $\mathrm{MoO}_{4}{ }^{2-}$. The surface oxidation layer on the molybdenum powder becomes thin; thus, it is assumed that the elution will be repeated in the case of an oxide of molybdenum, which becomes molybdenum (IV), (V) and (VI), which are generated in water. To conclude, the improvement of the yield can be expected by selecting the doping process at a low temperature to prevent molybdenum oxidation, wherein the powder with a few initial oxidations is used to reduce the elution amount.

\section{References}

1) M. Endo, K. Kimura, T. Udagawa, S. Tanabe, and H. Seto: "The Effects of Doping Molybdenum Wire with Rare Earth Elements", $12^{\text {th }}$ International Plansee Seminar '89 proceedings, Reutte, 1(1989)37-52.

2) M. Katoh, K. Hayashi, T. Araki, M. Yoshida, M. Fukuda,
N. Ayukawa, K. Koda, and T. Kikuchi: "Molybdenum Powder Elution Behavior to Water", J. Jpn. Soc. Powder Powder Metallurgy, 57(2010)485-491.

3) M.C. Abello, A.P. Velasco, O.A. Ferretti, and J.L. G. Fierro: "A Monte Carlo Approach to Describe the Reduction Profiles of Bidimensional MoOx Structures Grown on an Alumina Substrate", Latin Amer. Appl. Res., 37(2007)307.

4) P.A. Spevack and N.S. McIntyre: "A Raman and XPS Investigation of Supported Molybdenum Oxide Thin Films. 1 Calcination and Reduction Studies", J. Phys. Chem., 97(1993)11020.

5) S. Shoji, K. Okamura, and M. Inoue: "The Molybdenum Removal Efficiency of the Coagulating Sedimentation with Calcium Addition Method Used to Treat Wastewater Containing Molybdenum", Kanagawa-ken Kankyokagaku-center Kenkyu-Houkoku, 25(2002) 47.

6) I. Saito: "Studies on Oxidation, Reduction and Adsorption of Metallic Ions in Aqueous Solutions by Activated Carbons and the Like", Report of the National Research Institute for Pollution and Resources, 45 (1989) 26-33.

7) F.A. Cotton and G. Wilkinson: Advanced Inorganic Chemistry, A Comprehensive Text, 5th ed., John Wiley \& Sons, Inc., New York, (1988) 824-825.

8) T.A. Patterson, J.C. Carver, D.E. Leyden, and D.M. Hercules: "A Surface Study of Cobalt-MolybdenaAlumina Catalysts Using X-Ray Photoelectron Spectroscopy", J. Phys. Chem., 80(1976) 1700-1708. 